\title{
Mitochondrial DNA characterisation of European isolates: The Maragatos from Spain
}

\author{
José M Larruga ${ }^{\star, 1}$, Fernando Díez ${ }^{2}$, Francisco M Pinto ${ }^{1}$, Carlos Flores ${ }^{1}$ and Ana M González ${ }^{1}$ \\ ${ }^{1}$ Departamento de Genética, Universidad de La Laguna, 38271 La Laguna, Tenerife, Spain; ${ }^{2}$ Centro de Salud de \\ Astorga, León, Spain
}

\begin{abstract}
Mitochondrial DNA analysis confirms that Maragatos from Spain are a genetically isolated human group. Genetic distances between Maragatos and the comparison samples are significantly different even with the León sample $(P<0.001)$ which shares the same geographic area as the Maragatos. Although the northAfrican haplogroup U6 is present in them, their attributed Berber origin is weakened, as this haplogroup is also detected in surrounding populations with which, in addition, Maragatos have the smaller genetic distances. These U6 haplotypes are ascribed to a pre-historic African colonisation that influenced all the Iberian Peninsula. The presence of Neolithic haplogroups in this sample suggests that their isolation culture was not absolute until recent times. European Journal of Human Genetics (2001) 9, 708-716.
\end{abstract}

Keywords: human isolates; Maragatos; mtDNA; haplogroups

\section{Introduction}

The genetic characterisation of isolated populations is relevant to accomplish several scientific goals as those related to disease mapping, human diversity or human history. In Europe, the genetic heterogeneity of the Iberian Peninsula at mitochondrial DNA (mtDNA) level has been repeatedly confirmed, ${ }^{1,2}$ the Basques being the most outstanding and best studied population. ${ }^{2,3}$ The analysis of new Iberian isolates other than the Basques may help to unravel the relative influence that pre-historic and historic colonisers, with different geographic origins, had on the extant Iberian population. Here, we deal with one of these alternative groups, the Maragatos. Although very little is known outside Spain, the Maragato is one of the most interesting human cultural isolates in the Iberian Peninsula. They inhabit a western mountainous region in the province of León in the north of Spain (Figure 1). During the last century their census was steady around 10000 inhabitants, but in the last years this number has dropped to about 3000, mainly due to emigration. ${ }^{4}$ Nevertheless these emigrants faithfully con-

*Correspondence: Dr José M Larruga, Departamento de Genética, Facultad de Biología, Universidad de La Laguna, La Laguna, Tenerife 38271, Spain. Tel: +34 922318 351; Fax: +34 922318 311;

E-mail: jlarruga@ull.es

Received 20 November 2000; revised 10 May 2001; accepted 5 June 2001 serve their isolated and endogamic customs. That the Maragatos have developed agriculture in this area and itinerant merchant activity throughout the Iberian Peninsula since the Middle Ages are well-documented facts. ${ }^{5}$ Their cultural peculiarities with attributed resemblances to North African Berbers or to Near East Semitic cultures have differentiated them from their surrounding neighbours ever since. After sometimes bizarre etymological interpretations, today it is generally accepted that the name comes from their trading activity, as a popular derivative of the Latin word 'mercators' that is merchants, and has nothing to do with their ethnic origin. However, archaeological, anthropological and ethnographical studies point to an ancient human continuity in this area. ${ }^{5}$ At least three different interpretations about their origins have been proposed: (1) they are descendants of North African Berbers that settled in this area after the Moslem invasion; ${ }^{6}$ (2) they are Goths, allied to the Moslems, that adopted the Berber culture; (3) they have a Celtic ancestry as their surrounding neighbours, but with a differential Semitic component brought by the Phoenicians in pre-Roman times. The most interesting characteristic of the Maragatos is their cultural isolation that, due to their voluntary endogamy, has created a barrier against external marriages. This behaviour has presumably caused a genetic differentiation between this group and its neighbours by genetic drift. At the same time it might keep some genetic 


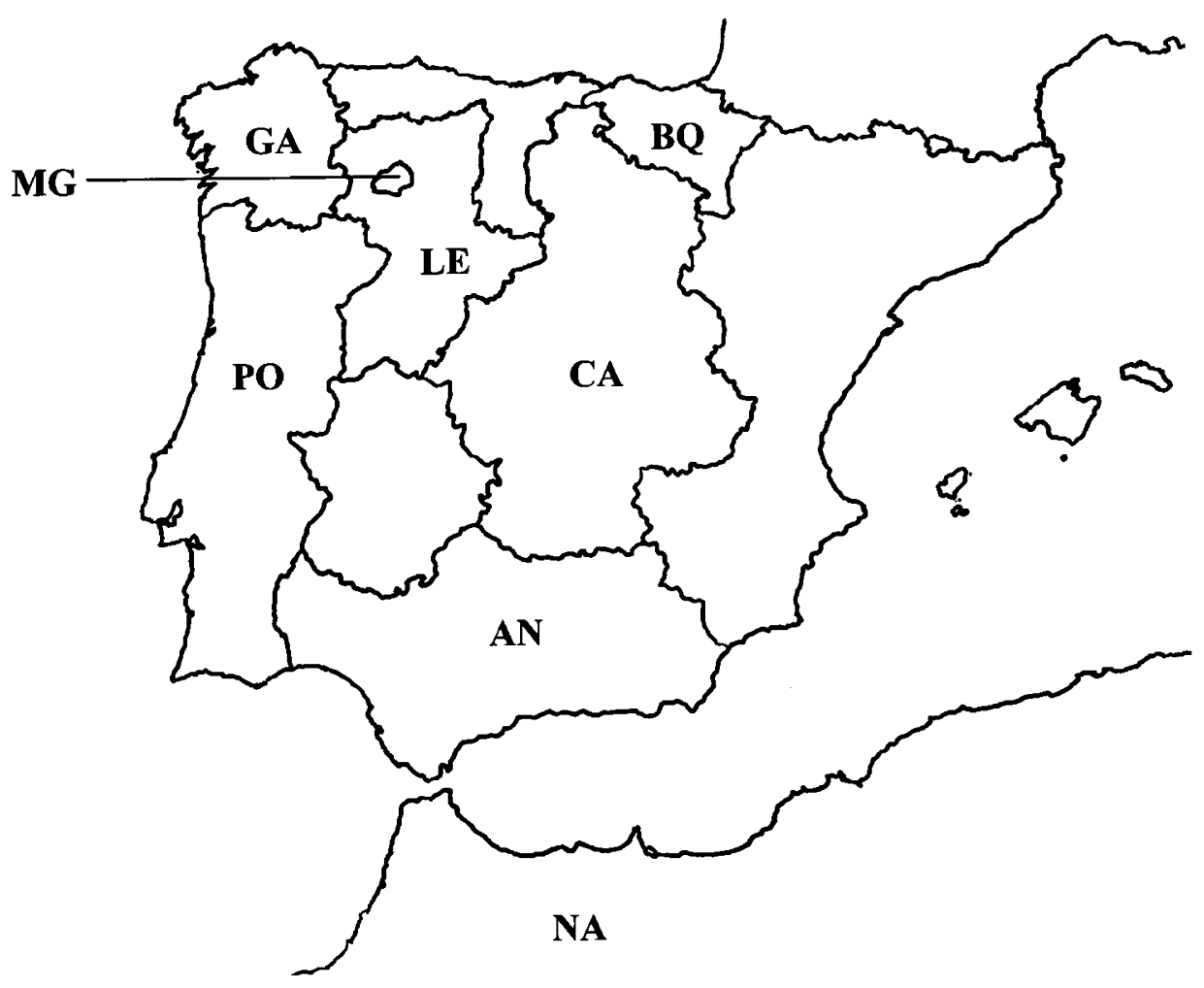

Figure 1 Geographic location of the populations sampled. Population codes as in Materials and methods

clues from their unknown ancestors. Fortunately, it is possible to test these suppositions from a molecular genetics perspective. Recent studies of maternally inherited mtDNA, based on restriction fragment length polymorphisms (RFLPs) and on sequences of the mtDNA hypervariable regions HVI and HVII, have revealed the sequence motifs which define the most common haplogroups and subhaplogroups. ${ }^{7}$ Some of them have their geographic origin well established ${ }^{8,9}$ and, therefore, can be used to reconstruct the genetic history and composition of extant carrier populations. The application of this type of analysis to find out the genetic structure and possible origin of the Maragatos is the principal aim of this study.

\section{Materials and methods Population samples}

A total of 198 unrelated individuals natural from different Iberian regions (Figure 1) voluntarily and anonymously donated blood for this study. Their origins were as follows: 49 Maragatos $(\mathrm{Mg})$ from the Astorga district, 61 individuals from the province of León (Le) (42 of them also from the Astorga district), 38 from Castile (Ca) and 50 from Andalusia (An). In addition, published and unpublished data from other populations as detailed in their references, were incorporated in the analysis: 353 Portuguese (Po) ${ }^{2}$ (González et al, personal communication), 135 Galicians (Ga) ${ }^{10}$ (González et al, personal communication), 167 Basques $(\mathrm{Bq})^{2,3,11,12}$ (Larruga, personal communication), 349 North Africans (NA) ${ }^{2,8,13}$ (Larruga, personal communication), and 15 Andalusians. $^{2}$

\section{Sequencing}

Total DNA was isolated from $5 \mu$ of blood, ${ }^{14}$ PCR amplified, ${ }^{15}$ and directly sequenced for both complementary strands. ${ }^{8}$ The sequences of $403 \mathrm{bp}$ of the first hypervariable segment (HVSI) of the control region of the mtDNA, from position 15997 to $16399,{ }^{16}$ were determined and aligned. To discriminate for ambiguous haplogroup classification, all individuals, sorted by sequence motif as $\mathrm{H}$ or $\mathrm{U}^{17}$ were also analysed by restriction for the polymorphic site $12308^{17}$ and for site $73,{ }^{18}$ the latter characterised using the L29 (5'gTCTATCACCCTATTAACCAC-3') and H408 (5' TgTTAAAAgTgCATACCgCCA-3') primers and the Alw44 I restriction enzyme. When ambiguity in haplogroup sorting persisted, the following additional sites were tested: 7025

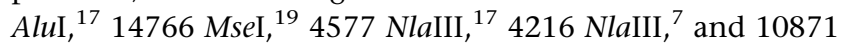
MnlI. ${ }^{20}$

\section{Phylogenetic analyses}

Gene diversity was measured as $\mathrm{H}$ values. ${ }^{21}$ Pairwise population comparisons were estimated as linearized Fst 
distances as implemented in the ARLEQUIN program, considering mtDNA as one locus with as many alleles as different haplotypes detected.

\section{Phylogeographic analyses}

All the sequences used in this study have been sorted into molecular clusters (haplogroups). ${ }^{7}$ Relative frequency of identical sequences (matches) among and between areas, within haplogroups with assigned geographic origin, ${ }^{7}$ has been used to refine the global affinities obtained from Fst distances.

\section{Results}

\section{Global analysis}

Table 1 lists our 198 analysed sequences according to their haplogroup status. The number of different sequences to the sample size rate is the lowest in Maragatos (0.49) and the highest in Andalusian (0.92) reaching habitual levels in León (0.69) and Castile (0.76). In a similar vein, values of gene diversity $(\mathrm{H})$ are significantly lower in Maragatos (0.87) than in any other population $(0.9460 \pm 0.0066)$ confirming at genetic level the historic endogamy attributed to the Maragatos. Table 2 shows the pairwise Fst distances between all the samples used in this study. The CRS sequence accounts for 91\% of all matches. Differences in frequency for this haplotype, that ranges from Maragatos (0.31) to Andalusian (0.14) and North Africans (0.12) play a determinant role on the Fst values, for this, distances have been calculated with (above the diagonal) and without (below diagonal) CRS. Three populations are significantly well differentiated: North Africans for which geographic and cultural barriers with the Iberian Peninsula have always existed, and the two Iberian recognised outlayers: Basques and Maragatos. The latter has smaller distances with the geographically closer populations of León, Galicia and Portugal (Figure 1) than with Andalusia or North Africa, weakening the hypothesis of a Berber origin for the Maragatos. On the other hand, although the lowest distance of Maragatos is with León, this is the highest distance that León has with any other Iberian population. This data can be taken as the second proof of the genetic isolation of Maragatos. As from now, due to the lack of significance and relative geographic proximity (Figure 1), Galicia and Portugal will be merged as West Peninsula (WP) and León-Castile as Center Peninsula (CP).

\section{Phylogeographic analyses}

Table 3 presents the relative frequency by area of haplogroups with geographic and/or temporal founder assignation. ${ }^{7,11,22}$ Both frequencies and the distribution of matches among them give new insights into the nature of the maternal genetic affinities among areas. In the Iberian Peninsula, Maragatos have the greatest frequencies for U5a1a, $\mathrm{J}^{*}$ and, excepting Basques, $\mathrm{H} / \mathrm{HV}^{*} / \mathrm{U}^{*} / \mathrm{R}^{*}$, but this is due to the presence of only one or a few haplotypes in high frequency
(Table 1), which, again supports their genetic isolation, as the lack of representation for some widespread sub-haplogroups as V. The distribution of U6 deserves special comment. This sub-haplogroup has a putative North African origin. ${ }^{2,8}$ In Europe it has only been detected in the Iberian Peninsula but with higher frequencies in northern than southern areas (González et al, personal communication) (Table 3). This distribution and its high diversity in Iberia has ruled out that historic events such as the Moslem occupation ${ }^{6}$ are the main causes of its presence in the Peninsula which has been attributed to a pre-historic African colonisation. Again its high frequency in Maragatos is due to only one haplotype that differs by five mutations from the one detected in neighbouring León. The same sequence has not been found in North Africa but is present once in our small Andalusian sample. Apart from $\mathrm{H} / \mathrm{HV}^{*} / \mathrm{U}^{*} / \mathrm{R}^{*}$, that represents $98.26 \%$ of all matches with greater mean values with northern $(23.59 \pm 0.80)$ than southern $(13.74 \pm 1.58)$ populations, Maragatos present other interesting matches. They share exclusively with Basques the widespread haplotype $T^{*} 126$, 294,296 , and the infrequent $T^{*} 294,296,304$ that apart from this area has only been detected in Sardinia. Other matches with northern, including Basques, but not southern areas include widespread haplotypes within U2 and W. Matches, in which Basques are excluded, are within the relatively recent sub-haplogroups U5a $1^{*}$ and $\mathrm{J}^{*}$. Haplogroup frequencies in the other Iberian regions also show interesting clues about their relative influences. Andalusia and its neighbouring area in West Peninsula show the greatest sub-Saharan African influences. The high frequency of M1 haplotypes in Andalusia is worthy of mention. Haplogroup $M$ had $a$ probable East African origin from where it expanded to the East to India. ${ }^{20}$ However, the distribution of sub-haplogroup M1 is mainly African. It spread northwards to Egypt ${ }^{23}$ and west to Morocco and Senegal. ${ }^{24}$

The small number of haplotypes sampled does not allow an estimation of the time of arrival in southern Iberia. Other characteristics of Andalusia are its moderate frequency of CRS and in general of $\mathrm{H} / \mathrm{HV}^{*} / \mathrm{U}^{*} / \mathrm{R}^{*}$ (Table 3) more similar to North Africa than to northern Iberia, and the high contribution of lineages with a Neolithic arrival to Europe (T1, J1a*, J1b* and J2), some of them (J1b* and J2) characteristic of the Mediterranean area. ${ }^{22}$ Similarly, derivatives of the European haplogroup U5 with strong Mediterranean implantation have also relatively high frequencies in Andalusia. The opposite happens with Basques, where the absence of Neolithic representatives is outstanding. They lack $\mathrm{T} 1, \mathrm{U} 3$ and the majority of $\mathrm{J}$, although the basal $\mathrm{J}^{*}$ is present. On the other hand, cluster U5 is well represented in its basal branches U5* and U5a* but the more derived ones are absent. Relative sequence sharing with the other areas relates Basques first with Central Peninsula (Fst=0.0016) and second with West Peninsula (0.0060), showing more divergent values with Andalusia (0.0084) and North Africa (0.0139). Basques share with Central Peninsula-Andalusia mainly 
Table 1 HVS I haplotypes and RFLPs in Maragatos, Leonese, Castile and Andalusia samples

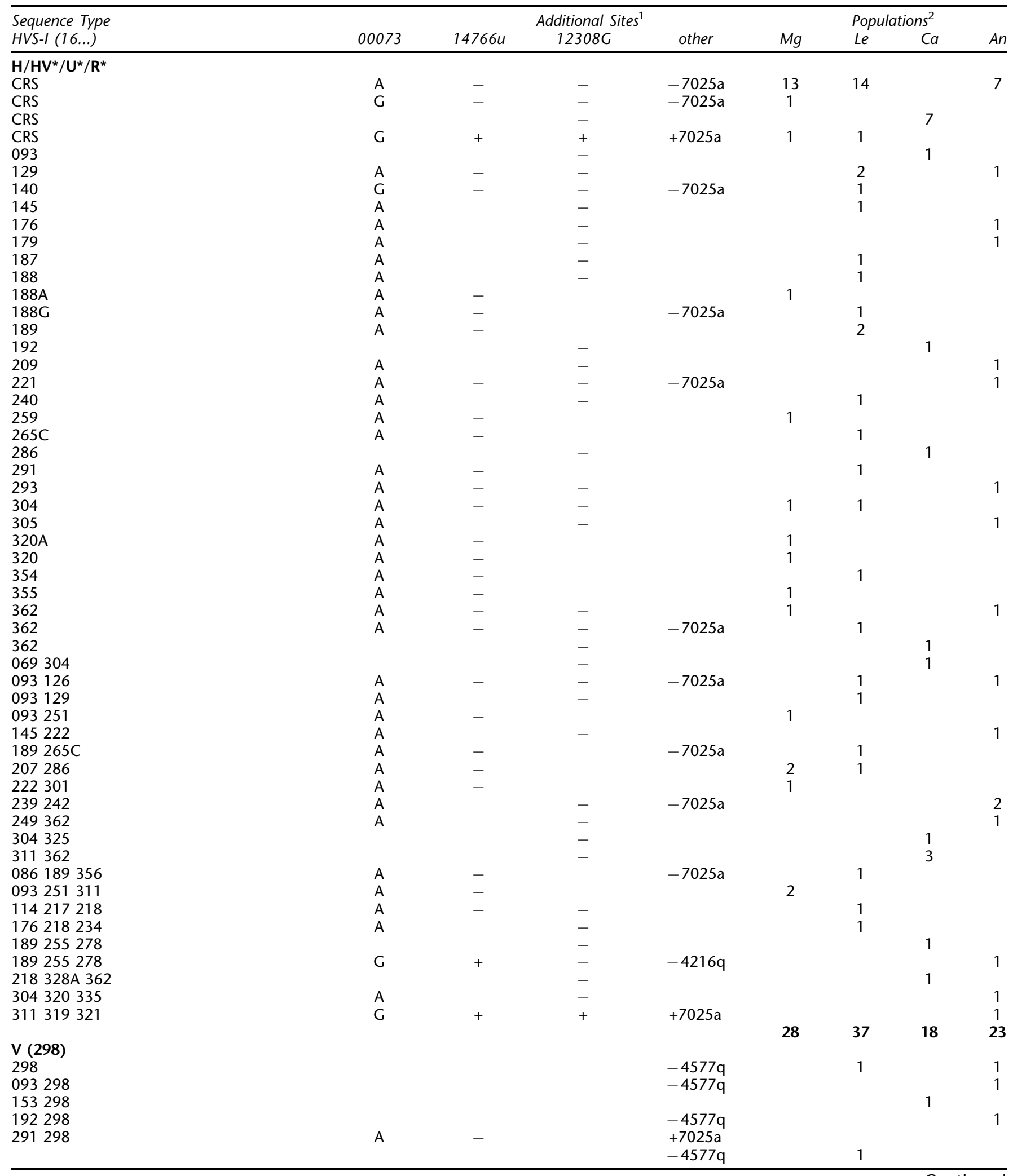


Table 1 (Continued)

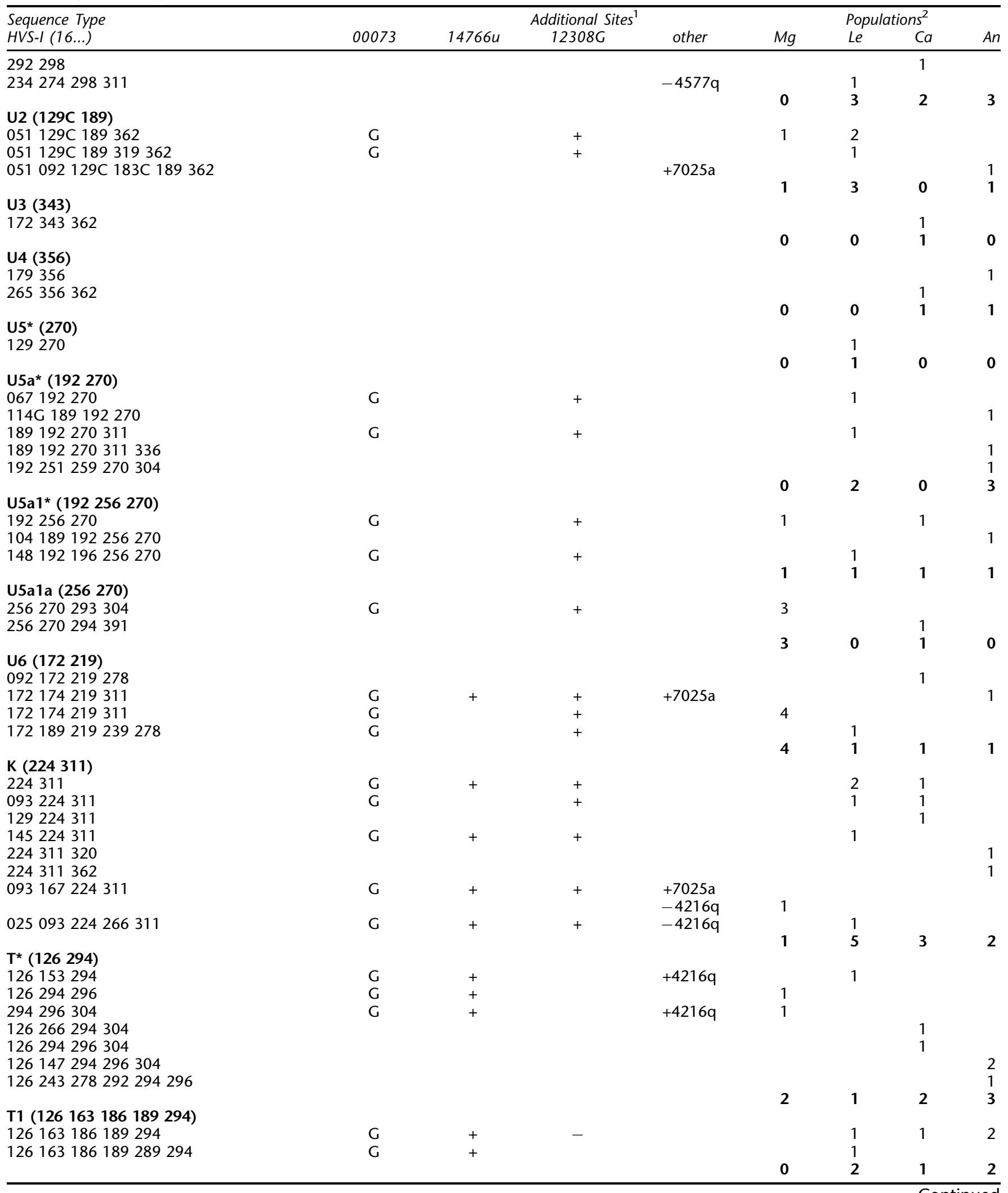


Table 1 (Continued)

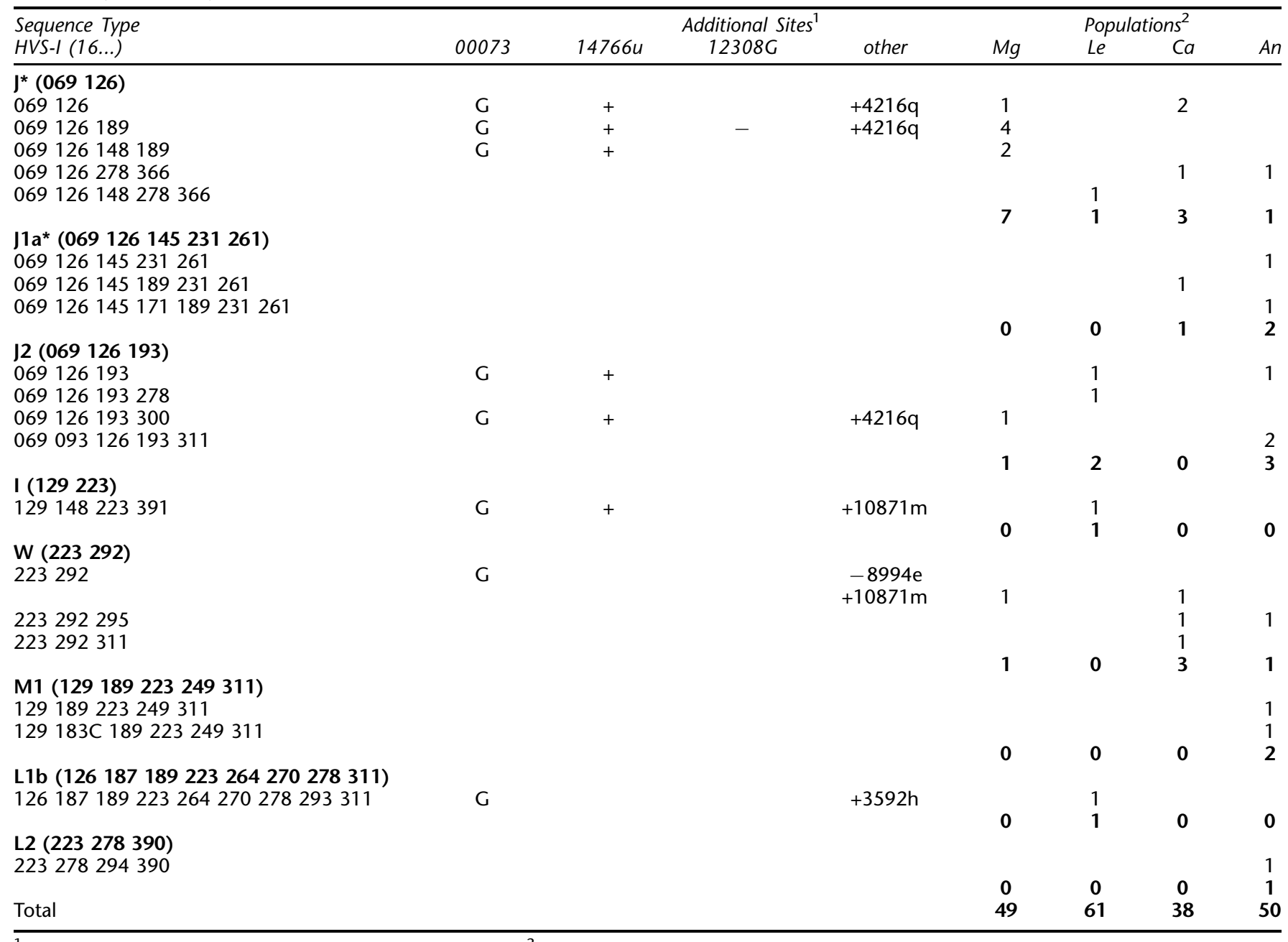

${ }^{1} \mathrm{a}=$ Alul; $\mathrm{e}=$ Haelli; $\mathrm{h}=$ Hpal; $\mathrm{m}=$ Mnll; $\mathrm{q}=$ Nlalli; $\mathrm{u}=$ Msel; ${ }^{2}$ population codes as in Materials and methods.

Table 2 Linearized $\mathrm{F}_{\mathrm{ST}}$ obtained when comparing the populations analysed for all the haplotypes (above the diagonal) and for all the haplotypes except the CRS (below the diagonal), and their signification. Population codes as in Materials and methods

\begin{tabular}{|c|c|c|c|c|c|c|c|c|}
\hline & Po & $G a$ & $M g$ & Le & $\mathrm{Ca}$ & $B q$ & $A n$ & $N A$ \\
\hline $\mathrm{Ga}$ & 0.00031 & & $0.01016^{*}$ & 0.00000 & 0.00000 & $0.00409^{*}$ & 0.00299 & $0.00837^{* * *}$ \\
\hline $\mathrm{Mg}$ & $0.01588^{\star * *}$ & $0.01720^{* * *}$ & & 0.00535 & 0.01211 & $0.01707^{* *}$ & $0.01950^{* *}$ & $0.02728^{* * *}$ \\
\hline $\mathrm{Ca}$ & 0.00212 & 0.00223 & $0.01597^{* *}$ & 0.00370 & & 0.00715 & 0.00000 & 0.00449 \\
\hline $\mathrm{Bq}$ & $0.01100^{* * *}$ & $0.00814^{\star \star *}$ & $0.02689^{\star \star \star}$ & $0.00653^{*}$ & $0.01443^{* *}$ & & $0.00839^{*}$ & $0.01392^{* * *}$ \\
\hline An & $0.00200^{*}$ & 0.00216 & $0.01557^{\star \star \star}$ & 0.00006 & 0.00112 & $0.01110^{* * *}$ & & 0.00343 \\
\hline
\end{tabular}

${ }^{*}=P<0.05 ;{ }^{* *}=P<0.01 ;{ }^{* * *}=P<0.001$

haplotypes belonging to $\mathrm{J}^{*}, \mathrm{~J}^{1 \mathrm{a}^{*}}$ and $\mathrm{U} 5 \mathrm{a}^{*}$, whereas with Central and West Peninsula they have the highest proportion of matches within $\mathrm{H} / \mathrm{HV}^{*} / \mathrm{U}^{*} / \mathrm{R}^{*}$, all within $\mathrm{U} 2$ and $\mathrm{X}$ and the basal haplotype $(223,292)$ of $\mathrm{W}$, all of them having a preNeolithic expansion in Europe. Finally, Central Peninsula seems to be well connected by maternal gene flow with the Atlantic area and with Andalusia. In fact, it is not significantly different from either of them (Table 2). The three areas account for all the matches in T1, U5a1*, J2 and derived haplotypes within $\mathrm{W}$, all with a probable Neolithic 
Table 3 Percentage of haplogroups and CRS in the different regions analysed. Population codes as in Materials and methods and Results

\begin{tabular}{|c|c|c|c|c|c|c|}
\hline Population & $N A$ & $A N$ & $W P$ & MG & $C P$ & $B Q$ \\
\hline Sample & 349 & 65 & 488 & 49 & 99 & 167 \\
\hline CRS & 11.75 & 13.85 & 22.34 & 30.61 & 22.22 & 20.96 \\
\hline $\mathrm{H} / \mathrm{HV}^{*} / \mathrm{U}^{*} / \mathrm{R}^{*}$ & 30.95 & 41.54 & 54.10 & 57.14 & 55.56 & 62.28 \\
\hline pre-*HV (126 362) & 0.86 & & 1.02 & & & \\
\hline V (298) & 5.16 & 4.62 & 3.48 & & 5.05 & 10.18 \\
\hline U1 (249) & 0.29 & & & & & \\
\hline U2 (129C 189) & & 1.54 & 1.02 & 2.04 & 3.03 & 0.60 \\
\hline U3 (343) & 3.15 & & 1.02 & & 1.01 & \\
\hline U4 (356) & & 1.54 & 1.43 & & 1.01 & \\
\hline U5* $(270)$ & 0.57 & & & & 1.01 & 0.60 \\
\hline U5a* (192 270) & 1.15 & 4.62 & 1.43 & & 2.02 & 11.38 \\
\hline U5a1* (192 256270$)$ & 0.86 & 3.08 & 0.82 & 2.04 & 2.02 & \\
\hline U5a1a (256 270) & & & 0.41 & 6.12 & 1.01 & \\
\hline U5b (189 270) & 1.15 & & 0.61 & & & \\
\hline U6 (172 219) & 14.90 & 1.54 & 2.05 & 8.16 & 2.02 & 0.60 \\
\hline U7 (309 318T) & & & & & & 0.60 \\
\hline $\mathrm{K}(224311)$ & 3.44 & 7.69 & 6.15 & 2.04 & 8.08 & 3.59 \\
\hline $\mathrm{T}^{*}(126294)$ & 2.87 & 4.62 & 5.74 & 4.08 & 3.03 & 4.79 \\
\hline T1 (126 163186189 294) & 2.29 & 4.62 & 2.46 & & 3.03 & \\
\hline$J^{*}(069126)$ & 3.15 & 1.54 & 4.51 & 14.29 & 4.04 & 1.80 \\
\hline 1 1* (069 126 261) & 0.29 & & & & & \\
\hline J1a (069 126145231 261) & 0.57 & 3.08 & & & 1.01 & 0.60 \\
\hline J1b* (069 126145222261$)$ & 0.29 & 3.08 & 0.20 & & & \\
\hline J1b1 (069 $126145172 \quad 222 \quad 261)$ & & & 0.61 & & & \\
\hline J2 (069 126193$)$ & & 4.62 & 1.23 & 2.04 & 2.02 & \\
\hline N1b (145 176G 223) & 0.29 & & 0.20 & & & \\
\hline I (129223) & & 1.54 & 0.82 & & 1.01 & \\
\hline W (223 292) & 0.29 & 3.08 & 2.46 & 2.04 & 3.03 & 1.20 \\
\hline X (189 223278$)$ & 1.15 & 1.54 & 1.23 & & & 1.20 \\
\hline $\mathrm{L} 3^{*}(223)$ & 2.29 & & 1.23 & & & 0.60 \\
\hline L3b (124 223278362$)$ & 2.29 & & 0.61 & & & \\
\hline L3d (124 223) & 0.86 & & & & & \\
\hline L3e $(172223320)$ & 1.15 & & 1.02 & & & \\
\hline M1 (129 189223249311$)$ & 2.29 & 4.62 & 0.41 & & & \\
\hline L1a (129 $\left.148 \quad 172187 \quad 188 G \begin{array}{lllll}189 & 223 & 230 & 311\end{array}\right)$ & 0.57 & & & & & \\
\hline 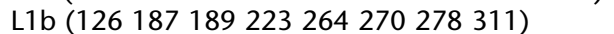 & 6.59 & & 1.23 & & 1.01 & \\
\hline L1c (129 $189223278294311 \quad 360)$ & 0.57 & & 0.20 & & & \\
\hline L2 (223 278 390) & 9.74 & 1.54 & 2.25 & & & \\
\hline
\end{tabular}

expansion. On the other hand, matches between West and Central Peninsula with Andalusia excluded, are within $\mathrm{T}^{*}$ and $\mathrm{J}^{*}$.

\section{Discussion}

It is confirmed at genetic level that the Maragato is a divergent human isolate in the Iberian Peninsula. Genetic drift due to small population size and voluntary endogamy seems to be the main cause of this isolation. As a consequence, rare haplotypes have reached notable frequencies in this population. In relation to its origin some hypotheses may be discarded. The presence of sub-haplogroup U6 of North African ascription does not make them different from their Iberian neighbours that also have U6 representatives, in fact an identical sequence has been found in Andalusia but not in North Africa. Therefore, a recent origin of the Maragatos as descendants of North African Berbers established in the Iberian Peninsula after the Moslem invasion and remaining since then isolated can be ruled out, at least for the ancestral maternal component of the population. However, what seems to be true is that Maragatos share with the majority of the Iberians an ancient North African influence. The fact that this North African input did not go beyond the Pyrenees is also against the hypothesis that the Maragatos were Goths that helped the Moslem invaders and assumed the Berber culture. Certainly Goths conquered the Iberian Peninsula around 600 A.D. after the fall of the Roman Empire but they were only a dominant elite with small demographic impact on the indigenous Iberian population. In spite of important drift effects it has been demonstrated that the Maragatos share a common genetic background with their surrounding neighbours, mainly from León but also from Galicia and Portugal. Haplotypes with a 
Neolithic dispersion are present in the Maragatos. This proves that their ancestors were a permeable group in Neolithic times, however we have not detected any haplotype with an exclusive Near East ascription, which could support a differential Semitic component with its neighbours. What genetics cannot explain is from where, when and why the Maragatos adopted their peculiar and isolated culture.

The analyses of new Iberian samples has also helped to clarify the nature and level of the previously detected mtDNA regional heterogeneity in Iberia. ${ }^{2,3}$ The Basque is another Iberian outlier better studied than Maragatos. Our comparative analysis is in agreement with the hypothesis that they represent a Palaeolithic isolate with little Neolithic demic input as deduced from the shortage of Neolithic lineages $(2.4 \%)$. It is also in favour of the existence of a common genetic background between Basques and other Iberian populations as has been repeatedly proposed ${ }^{2,25,26}$ and against the Georgian connection suggested on the basis of language concordances ${ }^{27}$ and on the relative sharing of some nuclear markers. ${ }^{28}$ Within the Iberian Peninsula, Basques have the smallest distances with their nearby populations of Central Peninsula and Galicia. With the same method employed here and using published sequences ${ }^{9,29-31}$ we calculated distances of Basques to Germans (Fst=0.016) and British (Fst=0.017) which are at least four times greater than those of Basques with León (0.003) or Galicia (0.004) and significantly different $(P<0.01)$ to them. Furthermore, it has recently been demonstrated, using mtDNA sequences, that Basques do not present a closer relation to Georgians than to the rest of European populations. ${ }^{32}$ Finally, the comparatively higher diversity of Andalusia that was previously detected in a small sample ${ }^{2}$ is confirmed here. Due to its geographical localisation, Andalusia has been a permanently open door to human movements since the Palaeolithic and this seems to be the most probable cause of its genetic complexity. In addition to the Palaeolithic substrate, Andalusia has by far the highest frequency (17\%) in the Iberian Peninsula of lineages expanded with the Neolithic $(\mathrm{J}+\mathrm{T} 1+\mathrm{U} 3)$ and a noticeable African influence (7.7\%) detected by the presence of lineages $(\mathrm{L} 2+\mathrm{M} 1+\mathrm{U} 6)$ originated in that continent.

\section{Acknowledgments}

We would like to thank Dr Carlos Vázquez Rojo, from Centro de Salud de Astorga, for helping us to obtain the Maragatos blood samples and to the two anonymous referees for their comments. This study was supported by grants of the DGES (PB96-1034) and Gobierno de Canarias (COF1999/019) to VM Cabrera.

\section{References}

1 Bertranpetit J, Cavalli-Sforza LL: A genetic reconstruction of the history of the population of the Iberian Peninsula. Ann Hum Genet 1991; 55: 51-67.
2 Côrte-Real HB, Macaulay VA, Richards MB et al: Genetic diversity in the Iberian Peninsula determined from mitochondrial sequence analysis. Ann Hum Genet 1996; 60: 331 - 350.

3 Bertranpetit J, Sala J, Calafell F, Underhill P, Moral P, Comas D: Human mitochondrial DNA variation and the origin of the Basques. Ann Hum Genet 1995; 59: $63-81$.

4 Sutil JM: Visita Pastoral año 2000. Arciprestazgo de la Somoza. Guía Eclesiástica del Obispado de Astorga. León, 2000.

5 Luengo A: Los maragatos. Su origen, su estirpe, sus modos. León, Ediciones Lancia, 1980.

6 Chejne AG: Muslim Spain. Its History and Culture. Minneapolis, Minnesota, University of Minnesota Press, 1974.

7 Macaulay V, Richards M, Hickey E et al: The emerging tree of West Eurasian mtDNAs: A synthesis of control-region sequences and RFLPs. Am J Hum Genet 1999; 64: 232-249.

8 Rando JC, Pinto F, González AM et al: Mitochondrial DNA analysis of Northwest African populations reveals genetic exchanges with European, Near-Eastern, and sub-Saharan populations. Ann Hum Genet 1998; 62: 531-550.

9 Richards M, Côrte-Real H, Forster P et al: Paleolithic and Neolithic lineages in the European mitochondrial gene pool. Am J Hum Genet 1996; 59: $185-203$.

10 Salas A, Comas D, Lareu MV, Bertranpetit J, Carracedo A: MtDNA analysis of the Galician population: a genetic edge of European variation. Eur J Hum Genet 1998; 6: 365-375.

11 Torroni A, Bandelt H-J, D'Urbano L et al: MtDNA analysis reveals a major late Palaeolithic population expansion from Southwestern to Northeastern Europe. Am J Hum Genet 1998; 62: $1137-1152$.

12 Richards M, Macaulay V, Hickey E et al: Tracing European founder lineages in the Near Eastern mtDNA pool. Am J Hum Genet 2000; 67: 1251-1276.

13 Watson E, Foster P, Richards M, Bandelt H-J: Mitochondrial footprints of human expansions in Africa. Am J Hum Genet 1997; 61: $691-704$

14 Rudbeck L, Dissing J: Rapid, simple alkaline extraction of human genomic DNA from whole blood, buccal epithelial cells, semen and forensic stains for PCR. BioTechniques 1998; 25: $588-$ 592.

15 Pinto F, González AM, Hernández M, Larruga JM, Cabrera VM: Genetic relationship between the Canary Islanders and their African and Spanish ancestors inferred from mitochondrial DNA sequences. Ann Hum Genet 1996; 60: 321-330.

16 Anderson S, Bankier AT, Barrell BG et al: Sequence and organization of the human mitochondrial genome. Nature 1981; 290: $457-465$.

17 Torroni A, Huoponen K, Francalacci P et al: Classification of European mtDNAs from an analysis of three European populations. Genetics 1996; 144: $1835-1850$.

18 Wilkinson-Herbots HM, Richards MB, Forster P, Sykes BC: Site 73 in hypervariable region II of the human mitochondrial genome and the origin of European populations. Ann Hum Genet 1996; 60: 499-508.

19 Lamminen T, Huoponen K, Sistonen P et al: MtDNA haplotype analysis in Finnish families with Leber hereditary optic neuropathy (LHON). Eur J Hum Genet 1997; 5: 271-279.

20 Quintana-Murci L, Semino O, Bandelt H-J, Passarino G, McElreavey K, Santachiara-Benerecetti AS: Genetic evidence of an early exit of Homo sapiens sapiens from Africa through eastern Africa. Nat Genet 1999; 23: 437 - 441.

21 Nei M: Molecular Evolutionary Genetics. New York, Columbia University Press, 1987.

22 Richards M, Macaulay V, Bandelt H-J, Sykes B: Phylogeography of mitochondrial DNA in western Europe. Ann Hum Genet 1998; 62: $241-260$.

23 Krings M, Salem AH, Bauer K et al: MtDNA analysis of Nile River Valley populations: A genetic corridor or a barrier to migration? Am J Hum Genet 1999; 64: 1166-1176. 
24 Flores C, Hernández M, González AM, Cabrera VM: Genetic affinities among human populations inhabiting the Subsaharan area, northwest Africa, and the Iberian Peninsula; in: ArnaizVillena A (ed): Prehistoric Iberia: Genetics, Anthropology, and Linguistics. New York, Kluwer Academic/Plenum Publishers, 2000, pp 33-50.

25 Martinez-Laso J, De Juan D, Martinez-Quiles N, Gomez-Casado E, Cuadrado E, Arnaiz-Villena A: The contribution of the HLA-A, $-B,-C$ and DR, -DQ DNA typing to the study of the origins of Spaniards and Basques. Tissue Antigen 1995; 45: 237-245.

26 Arnaiz-Villena A, Martínez-Laso J, Alonso-García J: Iberia: population genetics, anthropology, and linguistics. Hum Biol 1999; 71: $725-743$.

27 Lafon R: Concordances morphologiques entre le basque et les langues caucasiques. Word 1951; 7: $227-244$.

28 Bertorelle G, Bertranpetit J, Calafell F, Nasidze I, Barbujani G: Do Basque- and Caucasian-speaking populations share non-Indoeuropean ancestors? Eur J Hum Genet 1995; 3: 256-263.
29 Hofmann S, Jaksch M, Bezold R et al: Population genetics and disease susceptibility: characterization of central European haplogroups by mtDNA gene mutations, correlations with D loop variants and association with disease. Hum Mol Genet 1997; 6: $1835-1846$

30 Lutz S, Weisser HJ, Heizmann JP: Location and frequency of polymorphic positions in the mtDNA control region of individuals from Germany. Int J Legal Med 1998; 111: 67 - 77.

31 Piercy R, Sullivan KM, Benson N, Gill P: The application of mitochondrial DNA typing to the study of white Caucasian genetic identification. Int J Legal Med 1993; 106: 85 -90.

32 Comas D, Calafell F, Bendukidze N, Fañanás L, Bertranpetit J: Georgian and Kurd mtDNA sequence analysis shows a lack of correlation between languages and female genetic lineages. $\mathrm{Am}$ J Phys Anthropol 2000; 112: 5-16. 